\title{
1. Innovation management: perspectives from strategy, product, process and human resource research
}

Vida Škudienè, Jason Li-Ying and Fabian Bernhard

\section{INTRODUCTION}

Innovations and the ways to manage them in organizational settings are undoubtedly a hot topic these days. This interest is not surprising as creating new ideas and continuously innovating are key to differentiation in a more and more competitive marketplace. Many companies see innovation as their best and sometimes only chance to acquire a competitive advantage in the market.

Accordingly, managers of various types of organizations, public or private, are eager to learn about the latest trends, but find it challenging to keep up-to-date with current management knowledge in terms of guiding principles and best practices. They seek to develop their competencies particularly in innovation management in order to meet more effectively the growing demands from a highly competitive contemporary market. However, the ability to innovate often involves simultaneously managing product, processes, people and strategy. This can be challenging. Therefore, understanding how to manage innovation from a strategic perspective and meanwhile remaining focused on best practices in product development, process change, and human resource management becomes extremely important for managers.

Students in management, economics, social science and engineering are also interested in learning about innovation. Many business schools have set up specific programmes or courses on how to deal with innovations in organizations. Classes on entrepreneurship and creativity are popular in STEM (science, technology, engineering and mathematics) universities. Incubators at universities flourish and are seen as the source of new ideas and innovative businesses. And finally, academics are also interested in an overview of the latest findings from cutting-edge research in innovation management. 
Unsurprisingly the literature on these topics is abundant but finding one's way through the jungle of latest knowledge might be difficult. The present book tries to help students, academics, and practitioners by offering an up-to-date summary of innovation management with an integrated inner logic and a global perspective. In line with other scholars, we broadly define the concept of innovation as a new structure or management process, a policy, a new plan or programme, a new production process, or a new product or service produced in an organization. However, being different from many other volumes on the market, the present book examines innovation management through four unique perspectives - strategy, product, processes and people.

But why these four perspectives? How are they linked in terms of making sense of managing innovation? Consider Huawei Technologies Co. Ltd. (hereinafter Huawei), the Chinese multinational technology company, whose core businesses include telecommunications networks and equipment, and consumer electronics, including smartphones and laptops, headquartered in Shenzhen, Guangdong, China. Huawei made headline news in business and technology media a few years ago when it succeeded in the global $4 \mathrm{G}$ network market and became the world's second largest smartphone manufacturer behind Apple. Huawei is also taking a global leadership role in $5 \mathrm{G}$ wireless network technologies, as it holds the most $5 \mathrm{G}$ related patents and the largest market share of $5 \mathrm{G}$ network installation globally so far. Although Huawei could be criticized for using a copycat strategy during its early phase of business in the late 1980s and 1990s, after 30 years of development, there is no doubt that Huawei has become a global innovator. When asked how Huawei managed to succeed, according to a source from Huawei, the CEO of Huawei, Mr Zhengfei Ren, stated that:

Huawei has developed and succeeded, first and foremost, thanks to the business environment, the sectors that rapidly and extensively demand technologies and value creation. We then managed to make an effective strategy that captured the opportunities embedded in the environment, and then following the strategy, we hired a lot of talents, whom we have made the best use of based on effective incentive schemes, so that these highly talented and highly motivated people were able to develop new products that make sense to the market. We also paid attention to how to make these new products, the process must be right. When the new products are right, and the processes of making them are right, we can sustain competitive advantage against competitors. We then bring the return from the market back to new waves of continuous research and development $(R \& D)$, and this full circle goes on and on and on ... 
Mr Ren's view, more likely his management philosophy, on Huawei's success as such is perhaps the perfect answer to why we select strategy, product, processes and people as the four most critical aspects of innovation management to present to the readers. They are integrated parts of a coherent management logic as follows: the social, economic and political environments create potential business opportunities, which can only be grasped with an innovation strategy. Strategy further guides the direction of new product development by defining how radically new a product should be, what types of innovation are required to pull resources together and where the target market is. This usually is a journey of trial and error, which reflectively gives feedback to adapt the strategy. The process of reflective interaction between strategy and product innovation has a goal to 'get the right things'. In this process, technology is important but must serve the strategy and product innovation. Next, only getting the right things is not enough to achieve success - firms need to adopt new technology to increase efficiency and effectiveness. The process of innovation is about 'getting the things right'. Last but not least, and perhaps the most fundamental element in Mr Ren's mind, are the people, the human resources that drive innovation and meanwhile without losing control. Thus, human resource management (HRM) for innovation is about getting the right balance between control and incentive and about creating an innovative climate and culture.

The inner logic of innovation management that integrates the four critical aspects is illustrated in Figure 1.1 as an overall framework for this book, which is a collection of studies on each aspect. While understanding this integrated framework is important, readers who are interested in only a particular aspect can easily gain knowledge and insights by reading the respective chapter. The major questions addressed include: How to transform traditional human resource management by implementing innovative HRM systems? How to implement process and project innovation by integrating continuous improvement and business process re-engineering? How to manage the relationship between innovation performance and financial performance? What are the best management practices for a new product development? How to innovate through licensing? What can we learn from international industrial innovations experience?

\section{OVERVIEW}

This book offers new insights into the latest trends of innovation management in research and management. It consists of four parts that cover different perspectives and provide a holistic view across the key areas of innovation management. It illustrates the state of the art from the viewpoint of strategic innovation management, product innovation management, process innovation 


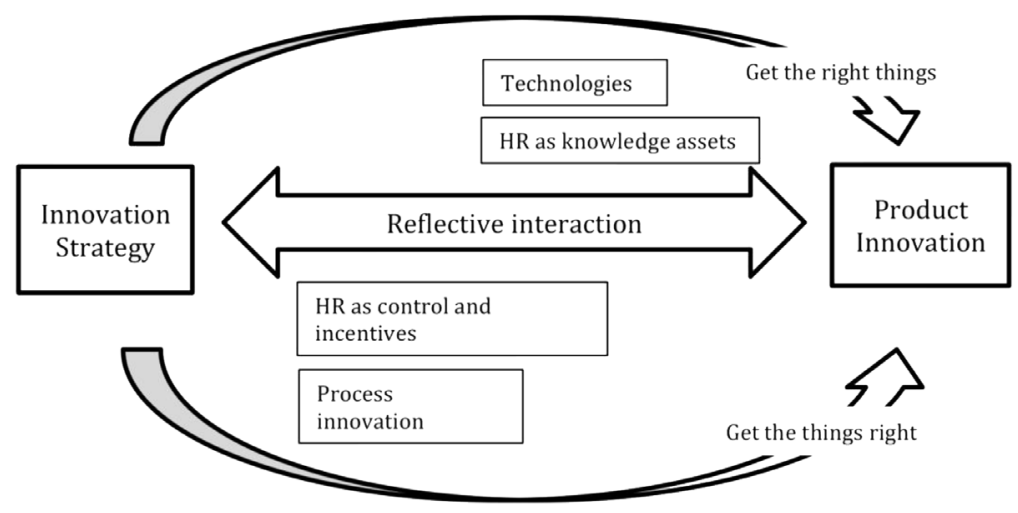

Figure 1.1 Conceptual framework of the book

management and human resource innovation management. Scholars from various countries in Europe (France, Denmark, Lithuania), Asia (China and Japan), and America (USA and Brazil) provide new understanding and research on the relevant topics, given their respective academic and practical backgrounds. They are experts in the field with knowledge on principles, strategies and applications in the specific area of innovation management.

The book addresses the four domains of the innovation management research, namely strategic, product, process and people. Readers are encouraged to look into the part that suits best their current needs or get inspiration by digging deeper into individual chapters. Management students at the master's level are offered a comprehensive overview on the topic that can stimulate the development of their innovation management skills. Academics can use this book to get a quick overview on the latest development in innovation management research and get inspired to seek new research directions. Practitioners, especially managers in large organizations, may also gain from reading this book, as it offers new insights for creating a sustainable innovation strategy to achieve competitive advantage in the long run. By offering an integrated framework with four key perspectives, this book can help practitioners to define and renew a winning innovation organization based on a sound understanding of the influential managerial elements.

After this introductory chapter, each part of the book focuses on a specific aspect of innovation management. Part II ('Innovation Management Strategy') provides insights into the strategic perspective. Chapters 2 and 3 put their emphasis on recent developments in the fast-moving Asian context. Chapter 
2 highlights the importance of using technology licensing to innovate in the context of China. Chapter 3 illustrates how Japanese companies strategize in order to innovate. Part III ('Product Innovation Management') deals with product innovation and its management. For many readers product innovation often represents the prominent core of innovation management. Chapter 4 explains the essentials of and best practices in new product development. Chapter 5 goes further by shedding light on product innovation with a concrete example of soft furnishing. Next, we learn in Chapter 6 about linkage between innovation and financial performance in the telecommunication industry. Part IV ('Process Innovation Management') is devoted to the management of process innovation. The key theme is how to achieve excellence in operational process innovation. Chapter 7 gives answers by examining integrated continuous improvements into processes and also looks at ways to re-engineer processes. Chapter 8 illustrates innovation processes by looking at system analysts as an example. Part V ('Human Resource Innovation Management') comprises three chapters on HRM and its impact on innovation. Chapter 9 shows us the advantages and challenges of implementing an innovative electric HRM system. Chapter 10 examines the relationship between HR practices and innovation. Effective HR practices towards innovation are discussed through an analysis of data from Brazil in Latin America. Lastly, Chapter 11 offers a micro perspective by presenting an overview on the role of human emotions in innovative behaviours. A case study of UPS Lithuania is presented in Part VI and provides an opportunity for the reader to consider this company's innovative approach to strategic, process, employee motivation and compensation management areas.

In the following discussion, each of these parts is presented in more detail. We conclude with final observations on the innovation management research perspectives and their international research value for the reader.

\section{Innovation Management Strategy}

Innovation management builds upon understanding the context of internal and external capabilities, the ever-changing uncertainties of future technology developments and competitive challenges. In formulating innovation strategies, organizations and companies have to take into consideration interorganizational, national and international systems and resources. The fundamental debate in innovation management is based on two contrasting approaches toward corporate strategy: rational and incremental. The supporters of the rational strategy approach see it as a linear model of rational action: appraisal, determination, action and focus on the analysis with complete understanding of the internal and external factors before taking strategic decisions. In contrast, incrementalists argue that companies may receive only some information 
from their environment and therefore must adapt their innovation strategy in the light of new knowledge and information following a three-step procedure: make deliberate changes towards the objective, measure and evaluate these changes, and adjust (if necessary) the objective before deciding on the next change.

The corporate innovation strategy according to Teece and Pisano (1994) incorporates three elements: (1) competitive and national positions; (2) technological paths; and (3) organizational and managerial processes. The more recent research by Jaruzelski et al. (2011) suggests that there is no single optimum strategy for innovation and distinguishes three clusters of observable good practice-based strategy: technology drivers, need seekers, and market readers. Technology drivers focus on developing new technologies; need seekers aim to be first in the market and focus on identifying customer needs and product development; and market readers seek to be the first followers and focus mainly on process innovation.

Part II explores the decisions about what innovation path is relevant for companies as they inevitably involve issues of strategic perspective and tend to be different across industries and countries. For example the Chinese approach to innovation management is based on learning from multinational companies established by the developed countries. Chinese innovation management follows the market reader approach. By employing technology licensing, managers seek to access external resources and pursue tight collaboration with local partners. In this approach, Chinese take a unique path to develop innovation capabilities. In Chapter 2 ('Innovation management through technology licensing in China'), Li-Ying et al. argue that this kind of innovation strategy should be recognized by companies when strategic decisions are being made. The authors, based on the research of State Intellectual Property Office of China (SIPO) data, provide insights and examples of the Chinese management practices used to innovate effectively and claim that technology licensing is a unique and successful innovation strategy.

A lot of research into innovation management strategy has focused on technological paths in the automotive industry context. Michael Hobday (1995) analysed modernization development in East Asian countries and provided arguments about how companies in these countries succeeded in rapid learning and technological innovation. His conclusions are illustrated by the examples of Japanese and Korean firms. In Chapter 3 ('Innovation management: the Japanese way'), Tadakuma et al. discuss Japanese innovation management principles and provide a case study of Toyota Motor Corporation's innovation management. The authors explore insights into Japanese innovation management peculiarities referring to the company's social contribution, lifetime employment, decision making by consensus, sense of community and Kaizen perspectives. The impact of cultural mentality on the uniqueness of Japanese 
management style is discussed through the lens of work by Peter F. Drucker, Teresa Amabile and Clayton Christensen.

In the era of globalization, companies must constantly pursue innovation in order to advance in the competitive market. Never before has the world witnessed the rate of economic growth exemplified by contemporary China and Japan. This fact calls for consideration of Chinese and Japanese innovation management analysis. The two chapters in this part are devoted to the insights of Chinese and Japanese scientists and business representatives into the unique innovation strategy employed by these countries. By learning from these countries' experience, managers may develop an effective innovation strategy and successfully compete in the global market.

\section{Product Innovation Management}

Extant literature indicates that product innovation is the key factor for company sustainable competitive advantage and success (Atalay et al., 2013; Gunday et al., 2011; Jimenez and Sanz-Valle, 2011). Fauji and Utami (2013) indicated that product innovation in particular helps businesses improve their operations, processes and performance. Previous studies emphasize the importance of product innovation management that, if perceived by customers as resulting in higher product quality, can affect the intention to purchase the product (Fauji and Utami, 2013). According to Zhang et al. (2013) truly innovative products create value for customers, generate higher margins, and increase customer equity. However, for different product categories, different nationalities and different external as well as internal factors, the results may differ. Thus, it is imperative not only to take into consideration the promotional activities of innovative products but also to clearly demonstrate to customers that the company itself is innovative. The analyses of product innovation management provided by the researchers in Part III highlight the specifics of strategies and practices across countries and industry sections.

Chapter 4 ('Exploring best practices of new product development') by Suzanne Conner gives an overview of best practices in the New Product Development process from inception to success. According to the author, as new firms enter the market while others attempt to remain competitive in the increasingly crowded global business landscape, developing and introducing new products are often utilized as an attempt to gain market share or edge out the competition. Developing new products for any firm is more difficult than managing existing product lines due to uncertainties surrounding them. For firms, especially startups, that may not have the knowledge of how to develop new products successfully or how to bring them to market, this can be very difficult. By having a clear understanding of best practices in the new product 
development arena, the firm may increase its chances of initial and repeated success.

Chapter 5 ('Product design innovation and functional innovation effects on consumers' adoption of soft furniture') explores the effect of design innovation and functional innovation on consumers' purchase intention and willingness to pay for soft furniture products. Recent decades have changed the business environment substantially due to the progress of globalization and increased competition, which have affected and changed the basis for companies' success. As a result, to be successful, it is crucial to know the extent to which consumers perceive the company and its products as innovative and how this impacts consumer product adoption. Exploration of these aspects requires investigation of the overall design effect (form and function) of a product and its perception more widely, rather than a single aspect of a design. This chapter explores the effect of design innovation and functional innovation on consumers' purchase intention and willingness to pay for the soft furniture products.

Chapter 6 ('Innovation and financial performance in telecommunication companies') analyses the relationship between product innovation and financial performance in the European telecommunications industry. However, innovation cannot be a goal in itself. Innovation projects must serve companies' strategic goals and, ultimately, lead to value enhancement. Exploring the link between innovation and financial performance, this study focuses on financial measures that are commonly used by investors and financial analysts. Most of them are profitability ratios that can be calculated from the financial statements of a company, such as return on equity (one of the key financial ratios for shareholders), return on assets and operating margin. Successful product innovation management requires a strong market orientation providing high quality products consistent with customers' needs, with attractive price and innovative product features. The results may be useful for researchers and managers of firms operating in a similar industry in order to determine key performance indicators for both innovation and profitability measures.

\section{Process Innovation Management}

Process innovation is a key management lever that can drive enterprise growth through increased productivity and asset utilization. It enables firms to continuously lower operational costs and creates more investment opportunities. Part IV focuses on process innovation as a key lever for extracting sustainable competitive advantages that could lower operational expenses and enable firms to bring products to market faster.

Chapter 7 ('Implementing process innovation by integrating continuous improvement and business process re-engineering') describes how firms can achieve process innovation through a combination of continuous improvement 
(CI) and business process re-engineering (BPR). While firms have often implemented CI in some functional areas, a comprehensive approach to $\mathrm{CI}$ is needed to drive process innovation. As better tools and methodologies become available firms can achieve significant operational improvement through the deployment of such tools. This adoption often results in a significant process restructuring, leading to the BPR approach. This chapter focuses on a range of process innovation activities and enables the development of a toolkit for process innovation, including Lean Six Sigma and the use of optimization tools and analytics.

Information Systems (IS) and Information Technology (IT) tools play a key role in driving process innovation and enable firms to achieve process excellence. Selection and deployment of appropriate IS can improve or break a company's operational processes, as evidenced by numerous high profile IS implementation failures. Traditionally, the process of IS development and deployment followed a Waterfall lifecycle where the entire process was split into a number of tasks that were performed serially. This caused significant delays and failures in deployment. Chapter 8 ('New role of systems analysts in Agile requirements engineering') explores Agile methodology, a new systems development and deployment process that focuses on continuous acceptance of changing functional requirements and delivery of small systems that can be rapidly tested, improved and deployed. The authors provide recommendations for the implementation of Agile methodology, focusing on the popular Scrum feature behind many Agile applications. Based on the current research, this chapter identifies the changes in knowledge and competencies required for system analysts to work effectively and collaborate successfully with various players in this new process framework.

The two topics in this part - the use of Agile methodology for rapid and successful implementation of modern IS and pursuing a combination of CI and business process restructuring - should be key tools in any business manager's toolkit for obtaining sustainable process innovation management benefits. These tools can play a major role in the more efficient use of resources and work towards a more sustainable economy.

\section{Human Resource Innovation Management}

In line with other organizational fields, human resource management has been subjected to rapid changes and the need to harness them as part of the strategic and tactical routine. Continuous technological development gives rise to multiple perspectives that affect human resource practice. Firstly, and perhaps most evidently, this trend results in subsequent technology- and internet-infused transformation of human resource management function, tools, methods and practices. Secondly, this shift calls for a reconceptualization of human resource 
inputs and outputs in the face of technologies, such as individual factors or broader phenomena. Part V covers three instances of the aforementioned transformation: innovative electronic human resource management value creation, the human resources management perspective on innovation, and the role of emotions in innovative and entrepreneurial behaviours.

The increasingly strategic role of human resource management and its subsequent evolution into electronic human resource management (or e-HRM) is evident in the vast number of companies that have adopted digital tools. Chapter 9 ('Transforming human resource management: innovative e-HRM value creation for multinational companies') presents an exploration of the transforming role of HRM and innovative value creation that is achieved through the employment of e-HRM practices. The chapter offers a body of insights accumulated through an empirical study conducted in multinational companies that are particularly sensitive to success and failures in HRM digitalization.

Chapter 10 ('Human resource management perspective on innovation') revisits two complex phenomena - innovation and human resource management. By drawing on the results of an empirical study conducted across 416 organizations in Brazil, the author explores the interplay between these phenomena. The chapter focuses on the alignment between the two: namely, how human resource management may be configured to yield different types of innovation, and how management innovations are embraced through multiple attributes. As a result, the study reveals the complexity of innovations from the perspective of human resource management, explores human resource management innovation and systematizes multiple innovation-related outcomes that stem from human resources.

Finally, the human side of innovations is inextricably linked with emotions that drive individuals involved in the ventures. Chapter 11 ('On the emotions that spark innovative and entrepreneurial behaviors in employees') explores the emotions that spark innovative and entrepreneurial behaviours. While this topic has attracted great interest across research and practice, the role of affect in entrepreneurial thinking and acting remains a nascent discipline. The author discusses the current developments in this field and guides us towards understanding the relation between affect and entrepreneurial cognition and behaviour. In this chapter, the author navigates between the different concepts of affect embedded in the notions of moods and emotions. The chapter outlines the key findings that will aid progress in addressing the role of positive and negative emotions, as well as the change of emotions in innovative and entrepreneurial cognition and behaviour.

Most business leaders and academics acknowledge the critical role that human resource management plays in the successful innovation management of organizations. New business models, industrial structures, and organi- 
zational systems require new ways of approaching and managing human resources. To deal with the challenges of these changes in line with rapid technological development and globalization, managers are forced to reconsider human resources as a basic building block in organizational frameworks designed for sustainable management of innovations. In order for the innovation framework to function sustainably, it is imperative that people effectively support the innovation aspirations. The insights of human resource management innovations present some basic human resource management tools that companies can use to develop innovation opportunities.

In Part VI, a case study of UPS Lithuania 'Choose your own salary' is presented. The company's innovative approaches to strategy, process, employee motivation and compensation management are explored. The discussion questions at the end of the case study refer to the relevant book chapters allowing the reader to compare the innovation management perspectives across the cultural and industrial lenses.

\section{CONCLUSIONS}

Innovation management is the management discipline that transforms creative ideas into market successes. While each case of innovation is contextualized, there are guiding principles and best practices for managers to follow, learn from, and adapt. This book suggests a conceptual framework that integrates strategy, product, process and human resource as four key and interrelated aspects of innovation management. Evidence and insights with a global scope are presented to readers who strive to find the most effective recipes to succeed in innovation.

Although the main takeaway from this book is that the winning strategy for innovation is to get the right things (product innovation) by getting the things right (process innovation) empowered by the right human resources, we must remind readers that there are more issues at stake in making such a winning strategy work. First of all, to grasp the business opportunities embedded in the environment by a sharp focus on the right product market and continuous adaptation of the strategy based on product-market feedback, a learning organization is needed. In other words, the capability of human capital to learn from fast-moving environments and turn uncertainty into knowledge is a key to the winning innovation strategy. A learning organization entails innovation leadership, effective and efficient decision making, risk-taking principles for project management, and an effective internal and external knowledge management system. Top management, mid-management, innovation officers, R\&D managers, and even front-line sales personnel must be part of the learning organization to accumulate and share knowledge, to turn knowledge into valuable assets. A learning organization can only be built on an effective 
incentive and performance measurement system. A learning organization requires continuous investment in people, because any other kinds of investment, even in the latest technology and machinery, will eventually become a cost, but investment in people who are motivated to learn will eventually lead to a return.

Second, too much attention has been paid by practitioners to seeking new ideas (for instance, the concept of 'idea competition' is quite often used by many large organizations), while focus on value creation and value capture is often overlooked or downplayed. Value creation for the customers and supply chain put the market and the industry at the centre of a business's logic, instead of considering what technologies and ideas a firm has that it can introduce to unidentified potential customers. Firms that bear value creation in mind as the starting point of their business logic will find the translation from its innovation strategy to the right product innovation easy and natural. In addition, value capture is equally as important as value creation. If created value does not yield any rent to the innovating firm, then value is not captured. This, in turn, will cause a firm to lose resources and motivation to further innovate. Value capture needs good insight and execution on business models, pricing, intellectual property appropriation and learning from external partners. Keep in mind that value capture needs a process - innovative organizations need to invest in human capital to develop capabilities for value capture. Companies may not lack ideas, but they may lack capabilities to bring the ideas through the innovation process to hit the right market.

The third critical element, implicitly embedded in our innovation framework, is about external collaboration. From new product development to adopting new operational processes, to finding the right engineers and marketing people, it is more and more difficult for a firm to innovate alone. Open innovation has become a standard format for innovation, while knowledge inflow and outflow are often used for product and service innovations. Firms need to learn how to acquire external knowledge (either by acquiring technology or acquiring knowledgeable persons), and how to profit from letting others use the firm's internal knowledge. What is external to a firm may become an internal asset, as long as an innovating firm has the capability and motivation to learn. External collaboration will extend a firm's resource base to external partners' and reduce the cost of new product development, if coordination is efficient. Thus, the benefit of open innovation is dependent on a firm's capability of managing external collaboration, for which investment in human resources and operation process is crucial.

Overall, a learning organization that pays sufficient attention to value creation and value capture by collaborative innovation will find it easy to link strategy, product, process and human resources based on a coherent business logic that naturally hosts and fosters innovation. To conclude, we would like 
to remind our readers that this book offers the best practices at present, but the best practices in the future are yet to come and to be explored, tested and adopted by future entrepreneurs and innovators - who could well be YOU!

\section{NOTE}

1. http://www.cghuawei.com/archives/11168.

\section{REFERENCES}

Atalay, M., N. Anafarta and F. Sarvan (2013), 'The relationship between innovation and firm performance: an empirical evidence from Turkish automotive supplier industry', Procedia - Social and Behavioral Sciences, 75, 226-235.

Fauji, M. and M. Utami (2013), 'How intellectual stimulation effects knowledge sharing, innovation and firm performance', International Journal of Social Science and Humanity, 3(4), 420-425.

Gunday, G., G. Ulusoy, K. Kilic and L. Alpkan (2011), 'Effects of innovation types on firm performance', International Journal of Production Economics, 133(2), 662-676.

Hobday, M. (1995), Innovation in East Asia: The Challenge to Japan, Cheltenham, UK and Northampton, MA, USA: Edward Elgar Publishing.

Jaruzelski, B., J. Loehr and R. Holman (2011), 'The Global Innovation 1000, Booz Allen Hamilton Annual Innovation Survey', Strategy and Business, 65. http://www.strategy-business.com/article/11404.

Jimenez, J.D. and R. Sanz-Valle (2011), 'Innovation, organizational learning and performance', Journal of Business Research, 64(4), 408-417.

Teece, D. and G. Pisano (1994), 'The dynamic capabilities of firms: an introduction', Industrial and Corporate Change, 3, 537-556.

Zhang, H., E. Ko and E. Lee (2013). 'Moderating effects of nationality and product category on the relationship between innovation and customer equity in Korea and China', Journal of Product Innovation Management, 30(1), 110-122. 